\title{
Malformations associated with congenital absence of the gall bladder
}

\author{
SUSAN BECKWITT TURKEL*, VIRGINIA SWANSON†, AND \\ PARAKARMA CHANDRASOMA* \\ From the Department of Pathology, University of Southern California School of Medicine, ${ }^{*}$ Los Angeles \\ County-USC Medical Center and †Children's Hospital of Los Angeles, Los Angeles, California, USA.
}

SUMMARY Thirty-four cases (29 children and five adults) of congenital absence of the gall bladder were found in a retrospective necropsy study. When the distribution of associated malformations in these patients was analysed, the cases were found to fall into several groups. The largest group (13) had multiple anomalies involving the genitourinary ( $83 \%$ reproductive tract, $42 \%$ renal), gastrointestinal (46\% imperforate anus, $23 \%$ tracheo-oesophageal fistula), cardiovascular ( $54 \%$ cardiac defects, $23 \%$ single umbilical artery), and skeletal (31\%) systems. Eight other patients had predominantly cardiac anomalies in addition to the agenesis of the gall bladder. Five had abnormalities associated with defects of the anterior abdominal wall. There were no additional malformations in the remaining cases. Family history was negative in all, suggesting a sporadic occurrence. Comparison with previously reported cases confirmed a similar distribution of anomalies. The hitherto unrecognised but consistent pattern of multiple malformations found with agenesis of the gall bladder may imply a non-random tendency for these defects to occur together.

Congenital absence of the gall bladder is a rare anomaly which may occur alone or in association with other malformations. ${ }^{1}$ Earlier studies have described a variety of defects associated with agenesis of the gall bladder, but in the majority of reported cases this anomaly is found alone and there has been no previous attempt to correlate the associated malformations. A retrospective necropsy search to identify cases of congenital absence of the gall bladder in our hospitals was undertaken. Analysis of the anomalies in these cases was performed, in order to study the frequency and pattern of the malformations associated with congenital absence of the gall bladder.

\section{Materials and methods}

The necropsy records at Los Angeles CountyUniversity of Southern California Medical Center (LAC-USC) and at the Children's Hospital of Los Angeles (CHLA) were reviewed. A total of 92600 necropsies performed at LAC-USC since 1920 was searched, 50780 cases from 1949 to 1979 with the aid of a computer, and the cases before 1949 and from 1979 to January 1982 manually. A total of 27

Received for publication 16 February 1983.

Accepted for publication 2 June 1983. cases with congenital absence of the gall bladder were found, five in adults and 22 in children of 18 months or less. The CHLA necropsy files from January 1960 to January 1982 were searched and seven cases of congenital absence of the gall bladder in children of 6 years of age or less were found. Cases of absent gall bladder associated with biliary atresia were excluded from the study.

After identification of the cases, the necropsies and histories were reviewed. Previously reported cases of congenital absence of the gall bladder and associated malformations were compiled. The results were tabulated and compared.

\section{Results}

The 27 cases of congenital absence of the gall bladder found among the 92600 necropsies in the files at LAC-USC represented an overall incidence of $1: 3400$ or $0.03 \%$. The five adult cases included four males and one female and ranged in age from 34 to 81 years. None had a history of biliary disease or surgery, and no external scars or fibrosis in the gall bladder fossa were found at necropsy. Hepatic morphology was normal. None exhibited any malformations, other than the presumably congenitally absent gall bladder. 
TABLE 1 Malformations with agenesis of the gall bladder: necropsy study population.

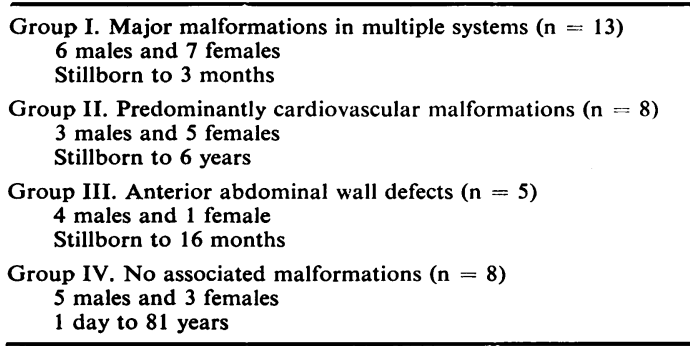

Of the 29 paediatric cases with agenesis of the gall bladder, 22 came from LAC-USC and seven from CHLA. There were three paediatric cases with only absent gall bladder and no other defects. This included one male and two females who ranged in age from one day to one month. Multiple malformations were found in the remaining 26 , who were found to fall into several groups (table 1). The largest group of 13 had multiple malformations involving the genitourinary, gastrointestinal, and cardiovascular systems. Eight cases had predominantly cardiac anomalies and five had malformations with defects of the anterior abdominal wall.

In the largest group, those with multiple major malformations, there were six males and seven females, ranging in age from stillborn to 3 months (table 2). Skeletal malformations were variable, with sirenomelia in one case, one case with phocomelia, two with milder upper limb defects, and one case with hemivertebrae. Two cases with cleft lip and palate were found in the group. Gastrointestinal anomalies were frequent and there were six cases with imperforate anus, three with malrotation, three with tracheo-oesophageal fistula, and one with pyloric stenosis.

Congenital heart disease was a very common finding in the first group. There were five cases with a ventricular septal defect and two with tetralogy of Fallot (one with a bicuspid aortic valve). There was one case with total anomalous pulmonary venous return, one with an atrial septal defect, one with anomalies of the aortic arch, and one with aortic and mitral stenosis. There were two cases with polysplenia and two vessel umbilical cords were noted in three infants.

Anomalies of the internal and external genitalia were frequent. Five of the seven females had severe anomalies, which included: a persistent cloaca; vesicovaginal fistula with double vagina; bicornuate uterus, cervix, and vagina with imperforate vagina and absent gonads bilaterally; absent bladder and
TABLE 2 Malformations with agenesis of the gall bladder: group $I$.

\begin{tabular}{|c|c|c|}
\hline & $\begin{array}{l}\text { Study } \\
(n=13)\end{array}$ & $\begin{array}{l}\text { Literature } \\
(n=11)\end{array}$ \\
\hline \multicolumn{3}{|l|}{ Gastrointestinal anomalies } \\
\hline Imperforate anus & 6 & 9 \\
\hline Tracheo-oesophageal fistula & 3 & 3 \\
\hline Abnormal pancreas & & 1 \\
\hline Malrotation & 3 & \\
\hline Pyloric stenosis (Down's) & 1 & \\
\hline \multicolumn{3}{|l|}{ Cardiovascular anomalies } \\
\hline Ventricular septal defect & 5 & 2 \\
\hline Tetralogy of Fallot & 2 & \\
\hline \multicolumn{3}{|c|}{ Anomalous pulmonary venous return 1} \\
\hline Atrial septal defect & 1 & 1 \\
\hline Anomalous aortic arch & 1 & \\
\hline Abnormal valves & 1 & 1 \\
\hline Single umbilical artery & 3 & \\
\hline \multicolumn{3}{|l|}{ Genitourinary anomalies } \\
\hline Abnormal internal genitalia & 5 & 7 \\
\hline Incomplete masculinisation & 4 & \\
\hline Gonadal agenesis & 2 & 1 \\
\hline Renal agenesis & 2 & 4 \\
\hline Renal dysgenesis & 3 & \\
\hline Renal hypoplasia & 1 & \\
\hline Urinary obstruction & 2 & 1 \\
\hline Horseshoe kidney & & 1 \\
\hline \multicolumn{3}{|l|}{ Skeletal and facial anomalies } \\
\hline Sirenomelia & 1 & \\
\hline Phocomelia & 1 & \\
\hline Vertebral anomalies & 1 & 1 \\
\hline Other limb defects & 2 & 2 \\
\hline Cleft lip and palate & 2 & 1 \\
\hline
\end{tabular}

uterus; and absent ovary and fallopian tube unilaterally. Hypospadias, shawl scrotum, microphallus, or unfused labioscrotal folds were found in four males. Renal anomalies were found in eight cases. These included renal dysgenesis, unilateral hypoplasia, and bilateral or unilateral agenesis in six, and hydronephrosis associated with urethral obstruction in two.

Karyotypes were performed in only three instances. In two cases the karyotypes were found to be normal. In one case, with clinical features compatible with this syndrome, trisomy 18 was documented. Trisomy 21 and trisomy 13 were suspected clinically in two cases, but were unconfirmed by karyotype analysis.

There were eight cases in whom congenital heart disease was the dominant defect found in association with congenital absence of the gall bladder (table 3). There were three males and five females in this second group, who ranged in age from stillborn to 6 years. The congenital cardiac defects included: truncus arteriosus with ventricular and atrial septal defects; tetralogy of Fallot; ventricular septal defect, either with aortic stenosis or tricuspid atresia or alone; and abnormal aortic and mitral valves. In association with these cardiac abnormalities, there 
TABLE 3 Malformations with agenesis of the gall bladder: group II.

\begin{tabular}{lll}
\hline & $\begin{array}{l}\text { Study } \\
(n=8)\end{array}$ & $\begin{array}{l}\text { Literature } \\
(n=4)\end{array}$ \\
\hline $\begin{array}{l}\text { Cardiovascular anomalies } \\
\quad \text { Ventricular septal defect }\end{array}$ & 3 & 1 \\
$\quad$ Tetralogy of Fallot & 2 & 1 \\
$\quad$ Atrial septal defect & 2 & 1 \\
$\quad$ Abnormal valves & 2 & \\
$\quad$ Truncus arteriosus & 1 & 1 \\
$\quad$ Coarctation of aorta & 1 & \\
$\begin{array}{l}\text { Genitoculare } \\
\quad \text { Renal dysinary anomalies }\end{array}$ & & \\
$\quad$ Horseshoe kidney & 2 & 1 \\
Gastrointestinal anomalies & 1 & \\
$\quad$ Abnormal pancreas & 1 & \\
\hline
\end{tabular}

were two cases with dysgenetic kidneys, one with an absent ear, one with a multilobed spleen, one with agenesis of the ventral pancreas, and one stillborn infant with meningomyelocele and horseshoe kidney.

The next group of cases included those in whom an absent gall bladder was found in association with defects of the anterior abdominal wall. There were two patients with omphalocele, one with gastroschisis, and two with severe but unspecified defects. They ranged in age from stillborn to 16 months. There were four males and one female in the group. Two showed severe skeletal malformations in association with the anterior wall defects, and an imperforate anus was found in one of these two. Intestinal malrotation was present in three. In two cases a ventricular septal defect was found, in one associated with abnormalities of the tricuspid and mitral valves. There was one case with an atrial septal defect. Hypospadias and microphallus were found in one case and bilateral renal dysgenesis was also observed once.

\section{Discussion}

Congenital absence of the gall bladder is a rare anomaly. Estimates of its incidence in the general population have ranged from 0.01 to $0.09 \%{ }^{2-4}$ Our observed incidence of $0.03 \%(1: 3400)$ at LAC-USC would be consistent with previous estimates. Congenital absence of the gall bladder is usually asymptomatic until later in life, when biliary symptoms may lead to cholangiography or surgery and the diagnosis being made. In children with serious malformations which result in early death, or in adults in whom the finding is incidental, gall bladder agenesis is usually diagnosed at necropsy. When absence of the gall bladder is collected from surgical experience in adults with biliary symptoms, associated malformations are rare, ${ }^{2}$ but when gall bladder agenesis is evaluated in necropsy series, associated malformations are more common. ${ }^{1}$

The largest series of cases of congenital absence of the gall bladder was reported by Monroe ${ }^{1}$ in 1959 , when he briefly described 181 cases of absent gall bladder, 77 in children less than one year old. These cases included some of biliary atresia and cystic fibrosis and were collected by a survey of pathologists from a total of 1352000 necropsies. In 117 of these 181 cases $(65 \%)$, gall bladder agenesis was associated with one or more other congenital anomalies. Gastrointestinal defects noted included tracheooesophageal fistula and annular pancreas, but not imperforate anus. Gonadal agenesis, renal agenesis and dysgenesis, and abnormalities of the internal genitalia in females and external genitalia in males were mentioned. Congenital heart defects, a variety of central nervous system anomalies including meningomyelocele, and skeletal malformations were also listed. ${ }^{1}$

The causes of the embryonic injury which could result in congenital absence of the gall bladder and the malformations associated with it are unknown and probably multiple. The liver, gall bladder, and biliary ducts are derived from a common ventral median outgrowth of the endodermal tube at approximately 2 weeks gestational age. This original diverticulum elongates, eventually becoming the hepatic and common bile ducts. The liver forms from a proliferation of cells at its anterior and ventral aspects. A second more caudal outgrowth from the original hepatic diverticulum, the cystic bud, forms during the fourth week. It gives rise to the gall bladder and cystic duct. ${ }^{5-8}$ Failure of the cystic duct to form or damage to it soon after could result in congenital absence of the gall bladder.

Although there was no known exposure to any drug or other teratogen in the necropsy cases in our study, agenesis of the gall bladder has been reported in association with thalidomide embryopathy. ${ }^{9}$ In addition to limb reduction defects, other malformations similar to those in our cases were found with drug exposure from 35 to 47 days' gestation. ${ }^{9}$ Absent gall bladder, malrotation of the bowel, imperforate anus, congenital heart defects, renal agenesis, and other genitourinary anomalies were observed with exposure during this period. ${ }^{9}$

Anomalies of the gall bladder may occur with karyotypic abnormalities. Hypoplasia of the gall bladder has been described in association with trisomy $18 . .^{10}$ In one of our cases of agenesis of the gall bladder, trisomy 18 was documented. Unfortunately the presumptive association with trisomy 21 and trisomy 13 could not be confirmed. 
In some instances, congenital absence of the gall bladder may be an inherited defect. There has been one report of agenesis of the gall bladder in members of a large kindred in whom this isolated defect appeared to be inherited as an autosomal dominant trait with reduced penetrance.11 There has been one report of a mother and daughter with gall bladder agenesis, ${ }^{12}$ and others of the occurrence of this anomaly in female sibs, ${ }^{13} 14$ but in the majority of cases gall bladder agenesis is sporadic. In none of our cases was there a family history of either gall bladder abnormalities or other congenital malformations.

The pattern of malformations seen with agenesis of the gall bladder is distinguishable from other recognised malformation syndromes. The $G$ syndrome is an $\mathrm{X}$ linked recessive disorder that is characterised by abnormal facies, laryngeal clefts, abnormal cry and swallow, hypospadias, and, in a few cases, congenital absence of the gall bladder and imperforate anus. ${ }^{15-17}$ There are also several similarities between the abnormalities seen with the VATER association and those found with agenesis of the gall bladder. ${ }^{18}{ }^{19}$ Imperforate anus, tracheooesophageal fistula, and renal and cardiac anomalies are encountered in both, but genital defects and absent gall bladder are not typically part of the VATER association. Polysplenia was found in two of the cases in our study. The occurrence of agenesis of the gall bladder with polysplenia ${ }^{20}$ and asplenia ${ }^{21} 22$ has been noted previously. Although no gall bladder may be found in approximately one-sixth of all cases of biliary atresia, ${ }^{23}$ malformations are rare and liver parenchymal changes are typical with this disorder. ${ }^{24}$

Excluding adults with only absent gall bladder and children with biliary atresia, 32 previously reported cases of congenital absence of the gall bladder were found to compare with our cases. ${ }^{22} 25-45$ When we compared these cases, we found the associated malformations to be similar in character and distribution to those in our own population. The cases could be grouped as ours were, with 11 showing major malformations of the gastrointestinal, cardiovascular, and genitourinary systems (table 2), ${ }^{22} 2830313437394144$ four with congenital heart disease (table 3), $22{ }^{31} 37$ and nine who had a variety of fewer malformations from the same spectrum (table 4). ${ }^{25} 26323640424345$ There were no cases found with anterior abdominal wall defects and absent gall bladder. The remaining reports described children of 3 years or less who had no other malformations. 2527293135 The majority of reported cases are adults with no other congenital defects.

Based on our necropsy experience and review of published reports a hitherto unappreciated but
TABLE 4 Malformations with agenesis of the gall bladder: reported cases with isolated associated defects.

\begin{tabular}{|c|c|}
\hline External anomalies & \\
\hline Meningomyelocele 26 & 1 \\
\hline Anencephaly25 & 1 \\
\hline Klippel-Feil45 & 1 \\
\hline Lumbar hernia 40 & 1 \\
\hline Gastrointestinal anomalie & \\
\hline Malrotation 363841 & 3 \\
\hline Genitourinary anomalies & \\
\hline Renal dysgenesis 32 & 1 \\
\hline Horseshoe kidney 42 & 1 \\
\hline
\end{tabular}

consistent pattern of malformations associated with agenesis of the gall bladder has emerged. This pattern and its distribution are similar in both our own population and in the previously reported cases. The largest group of cases exhibit the most severe anomalies in the spectrum. Finding the same pattern and distribution in both our own cases and in published reports would imply a non-random tendency for these multisystem defects to associate together. The majority of cases appear to demonstrate the most severe manifestation of the association. When cases occur with fewer defects, the anomalies are part of the same predictable spectrum of malformations associated with agenesis of theo gall bladder.

\section{References}

1 Monroe SE. Congenital absence of the gall bladder: a statistical study. J Int Coll Surg 1959;32:369-73.

2 Ferris DO, Glazer IM. Congenital absence of the gall bladder: 4 surgical cases. Arch Surg 1965;91:359-61.

3 Ahlberg J, Angilin B, Einarsson K, Leijd B. Biliary lipid composition and bile acid kinetics in patients with agenesis of the gall bladder with a note on the frequency of this anomaly. Acta Chir Scand [Suppl] 1978;482:15-20.

4 Yamashita T, Panebianco A. Agenesis of the gall bladder and review of the literature. Am J Gastroenterol 1966;46: 402-6.

5 Keibel F, Mall FP. The development of the liver. In: Manual of human embryology. Vol 2, chap 17. Philadelphia: Lippincott, 1912: 403-29.

6 Hayes MA, Goldenberg IS, Bishop CC. The developmental basis for bile duct abnormalities. Surg Gynecol Obstet 1958; 107: 447-56.

7 Lindner HH, Green RB. Embryology and surgical anatomy of the extrahepatic biliary tract. Surg Clin N Am $1964 ; 44: 1273-85$.

8 Gray SW, Skandalakis JE. Extrahepatic biliary ducts and the gall bladder. In: Embryology for surgeons. The embryologic basis for the treatment of congenital defects. Chap 8. Philadelphia: Saunders, 1972:229-62.

- Kreipe U. Missbildungen innere Organe bei Thalidomidembryopathie. Arch Kinderheilkd 1967;176:33-61.

10 Warkany J, Passarge E, Smith LB. Congenital malformations in autosomal trisomy syndromes. Am J Dis Child 1966;112:502-12. 
11 Nadeau LA, Cloutier WA, Konecki JT, et al. Hereditary gall bladder agenesis: 12 cases in one family. J Maine Med Assoc 1972;63:1-6.

12 Sterchi JM, Baine RW, Myers RT. Agenesis of the gall bladder: an inheritable defect? South Med J 1977;70: 498-9.

13 Kobacker JL. Congenital absence of the gall bladder-a possible hereditary defect. Ann Intern Med 1950;33: 1008-12.

14 Becker IW, Mastroni PP. Congenital absence of the gall bladder with a family history. Am Surg 1979;45:541-2.

15 Opitz JM, Frias JL, Gutenberger JE, Pellett JR. The G syndrome of multiple congenital anomalies. Birth Defects 1969;5:95-101.

16 Gilbert EF, Visekul C, Mossman HW, Opitz JM. The pathologic anatomy of the $G$ syndrome. $Z$ Kinderheilkd 1972;111:290-8.

17 Opitz JM. G syndrome. In: Bergsma D, ed. Birth defects compendium. 2nd ed. New York: Liss, 1979:453-4.

18 Quan L, Smith DW. The VATER association: vertebral defects, anal atresia, T-E fistula with esophageal atresia, radial and renal dysplasia: a spectrum of associated defects. J Pediatr 1973;82:104-7.

19 Temtamy SA, Miller JD. Extending the scope of the VATER syndrome. J Pediatr $1974 ; 85: 345-9$.

20 Moller JH, Nakib A, Anderson RC, Edwards JE. Congenital cardiac disease associated with polysplenia: a developmental complex of bilateral 'left-sidedness'. Circulation 1967;36:789-99.

21 Freedom RM. The asplenia syndrome: a review of significant extracardiac structural abnormalities in 29 necropsied patients. J Pediatr 1972;81:1130-3.

22 Gerwig WH, Countryman LK, Gomez AC. Congenital absence of the gall bladder and cystic duct. Ann Surg $1961 ; 133: 113-25$

23 Rabinovitch J, Rabinovitch $\mathbf{P}$, Rosenblatt $\mathbf{P}$, Pines $\mathbf{B}$. Rare anomalies of the extrahepatic bile ducts. Ann Surg 1958;148:161-8.

24 Landing $\mathrm{BH}$. Considerations of the pathogenesis of neonatal hepatitis, biliary atresia and choledochal cyst: the concept of infantile obstructive cholangiopathy. Prog Pediatr Surg 1974;6:113-39.

25 Canton E. Case of congenital deficiency of the gall bladder with observations. Lancet 1847 ;i : 406-8.

26 Simpson AR. Congenital absence of the gall bladder. Edinburgh Med J 1861;6:1045-6.

27 Eshner A. Congenital absence of the gall bladder. Med News 1894;64:548-9.

28 Blakeway $H$. Congenital absence of the gall bladder associated with imperfect development of the pancreas and imperforate anus. Lancet $1912 ; \mathbf{i i}: 365$.

29 Knox LC. Congenital absence of the gall bladder. Proc NY Pathol Soc 1922;22:166-73.
30 Jones RW. A case of imperforate anus with megacolon and terminal peritonitis. BrJ Surg 1926;13:575-8.

31 Stolkind E. Congenital abnormalities of the gall bladder and extrahepatic ducts: review of 245 reported cases with reports of 31 unpublished cases. Br J Child Dis 1939;36: $115-31$.

32 Zimmerman LE. Asymptomatic bilateral polycystic disease of the kidneys and congenital absence of the gall bladder: report of a case in a 70 year old patient with pancreatic carcinoma. Am Pract 1948;3:61-4.

33 Latimer EO, Mendez FL, Hage WJ. Congenital absence of the gall bladder: report of 3 cases. Ann Surg 1947; 126:229-42.

34 Moore TC, Lawrence EA. Congenital malformations of the rectum and anus. II. Associated anomalies encountered in a series of 120 cases. Surg Gynecol Obstet 1952; 95:281-8.

35 Pines B, Grayzel DM. Congenital absence of the gall bladder and cystic duct. Arch Surg 1958;77:171-80.

36 Reid DA. Congenital absence of the gall bladder associated with a high caecum and absence of ascending colon. Br Med J 1959;ii:1154-5.

37 Mcllrath DC, ReMine WH, Baggenstrass AH. Congenital absence of the gall bladder and cystic duct: report of ten cases found at autopsy. JAMA 1962;180:782-3.

38 Seifert KA. Congenital absence of the gall bladder and cystic duct. Wis MedJ 1963;62:259-62.

39 Frey C, Bizer L, Ernst C. Agenesis of the gall bladder. Am J Surg 1967;114:917-26.

40 Nghiem DD, Read RC. Agenesis of the gall bladder and congenital lumbar hernia. South Med J 1979;72:1151-3.

41 Haughton V, Lewicki AW. Agenesis of the gall bladder: is preoperative diagnosis possible? Radiology 1973;106: $305-6$.

42 Bietz D, Dillard D. Agenesis of the gall bladder, malrotation of the gut, and horseshoe kidney: a new syndrome? Am J Surg 1974;127:596-8.

43 Martinoli S, Schmitt HE, Allgower M. Eine engewohnliche Trias: Gallblasenagenesie, Pancreas anulare, und Pfortaderanomalie. Helv Chir Acta 1980;46:767-70.

44 Tveter KJ, Fonkalsrud EW, Goodwin WE. Single vaginal ectopic ureter and solitary kidney, associated with imperforate anus and other malformations: a case report. Scand J Urol Nephrol 1980;14:119-21.

45 Gajic SI. Gall bladder agenesis in a patient with KlippelFeil syndrome. Arch Pathol Lab Med 1981;105:682-3.

Correspondence and requests for reprints to $\mathrm{Dr}$ Susan Beckwitt Turkel, Department of Pathology, Los Ȧngeles County-USC Medical Center, Women's Hospital 1-M-19, Los Angeles, California 90033, USA. 